\title{
Mortality in Critically Ill Elderly Individuals Receiving Mechanical Ventilation
}

\author{
Roberto Santa Cruz, Fernando Villarejo, Alvaro Figueroa, Marcela Cortés-Jofré, Juan Gagliardi, \\ and Marcelo Navarrete
}

\begin{abstract}
BACKGROUND: Previous studies that evaluated mortality in elderly subjects who received mechanical ventilation had conflicting results. The aim of this systematic review was to evaluate the effects of age on mortality. METHODS: A number of medical literature databases and the references listed (from 1974 to May 2015) were searched for studies that compared 2 different age groups. The primary outcome was mortality in subjects ages $\geq 65 \mathrm{y}$. The severity scores, ICU and hospital lengths of stay, and the presence of ventilator-associated pneumonia were secondary outcomes. Finally, mortality in the subjects with ARDS and of cutoff ages 70 and $80 \mathrm{y}$ was assessed by subgroup analysis. Evidence quality was assessed by the GRADE (Grading of Recommendations Assessment, Development, and Evaluation) criteria score. RESULTS: Of the 5,182 articles identified, 21 were included. Subjects ages $\geq 65 \mathrm{y}$ had higher mortalities (odds ratio [OR] $1.80,95 \%$ CI 1.56-2.08; $\mathbf{I}^{2}=71 \%$ ). APACHE (Acute Physiology and Chronic Health Evaluation) II revealed intergroup differences (mean difference 3.07, 95\% CI 2.52-3.61; $\mathrm{I}^{2}=0 \%$ ), whereas neither the ICU nor hospital length of stay (mean difference $1.27,95 \%$ CI -0.82 to $3.36, I^{2}=82 \%$, and mean difference $1.29,95 \% \mathrm{CI}-0.71$ to $3.29, \mathrm{I}^{2}=0 \%$, respectively) nor the groups in the 2 studies that assessed ventilator-associated pneumonia exhibited any difference. Subgroup analysis revealed a higher mortality in the older subjects, in the subjects with ARDS (OR 1.76, 95\% CI 1.30-2.36; $\left.I^{2}=0 \%\right)$ and in the subjects ages 70 and $80 \mathrm{y}\left(\mathrm{OR} 1.78,95 \%\right.$ CI 1.51-2.10, $\mathrm{I}^{2}=71 \%$; and OR 1.96, 95\% CI 1.81-2.13, $\mathrm{I}^{2}=0 \%$, respectively). The quality of associated evidence was low or very low. CONCLUSIONS: Although low-quality evidence was available, we conclude that age is associated with a greater mortality in critical subjects who were receiving mechanical ventilation. Key words: elderly; mechanical ventilation; intensive care unit; outcome; age; systematic review. [Respir Care 2019;64(4):473-483. (C) 2019 Daedalus Enterprises]
\end{abstract}

\section{Introduction}

In recent decades, the proportion of the population $>60 \mathrm{y}$ old has steadily increased. These demographic changes

Drs Santa Cruz and Figueroa are affiliated with the Department of Intensive Care, Hospital Regional Rio Gallegos, Rio Gallegos, Argentina. Drs Santa Cruz and Navarrete are affiliated with the School of Medicine, University of Magallanes, Punta Arenas, Chile. Dr Villarejo is affiliated with the Department of Intensive Care, Hospital Nacional Prof. A Posadas, El Palomar, Argentina. Dr Cortés-Jofré is affiliated with the Facultad de Medicina, Universidad Católica de la Santísima Concepción, Concepción, Chile. Dr Gagliardi is affiliated with the Department of Cardiology, Htal Gral Dr. Cosme Argerich, Buenos Aires, Argentina.

This review was supported by Fondo Nacional de Desarrollo Científico y Tecnologico 1180882. resulted in higher admission rates to ICUs of elderly patients. Current estimations indicate that two thirds of all bed-days in ICUs in the developed world have been allocated to patients ages $>65 \mathrm{y} .{ }^{1}$ Moreover, in certain countries, such as Australia and New Zealand, between 10 and

The authors have disclosed no conflicts of interest.

Supplementary material related to this paper is available at http:// www.rcjournal.com.

Correspondence: Roberto Santa Cruz MD, Department of Intensive Care, Hospital Regional Rio Gallegos, José Ingenieros 95, Rio Gallegos (CP 9400), Santa Cruz, Argentina. E-mail: resc.hrrg@ gmail.com.

DOI: $10.4187 /$ respcare. 06586 
$15 \%$ of the ICU beds are occupied by patients $>80 \mathrm{y} .{ }^{2}$ Because these patients have a high requirement for mechanical ventilation, the impact of this intervention on mortality deserves considerable evaluation. The existing evidence regarding elderly patients on ventilation has not yet allowed definitive conclusions to be drawn.

Although some studies indicated that age had a detrimental effect on the outcomes of subjects who received mechanical ventilation, ${ }^{2,3}$ other studies revealed no association. ${ }^{4,5}$ Moreover, most of the studies available are observational, in which data are not adjusted for confounders and included subjects with a wide range of pathologies (ie, with case mix). Therefore, we conducted a systematic review and meta-analysis to evaluate the mortality rate of subjects in the ICU ages $\geq 65 \mathrm{y}$ who received mechanical ventilation compared with subjects ages $<65$ y. Moreover, in the meta-analysis conducted, the subjects with ARDS or with higher cutoff points for age were also considered.

\section{Methods}

The protocol was registered on PROSPERO (Centre for Reviews and Dissemination University of York, York, UK; CRD42015020568) in October 2015, and, subsequently, updated in October 2017. The systematic review was conducted according to the checklist of the Meta-analysis of Observational Studies in Epidemiology group. ${ }^{6}$ A systematic search was performed in (May 2015) MEDLINE (National Library of Medicine 8600 Rockville Pike, Bethesda, Maryland), Cochrane Central Register of Controlled Trials (Rigshospitalet, Copenhagen Denmark), and Embase (Elsevier BV Registered Office, Amsterdam, The Netherlands). We used a strategy that combined key words and descriptors (Medical Subject Headings or Embase Subject Headings) without language restriction. In addition, we screened the reference list of all the available review articles and primary studies. We also searched www.clinicaltrials.gov for ongoing studies and set the similar-articles option in PubMed (see the supplementary materials at http://www.rcjournal.com).

We included observational studies that compared 2 different age groups in the evaluation of mortality in subjects who were receiving mechanical ventilation while in an ICU. No language restrictions were imposed on the study selection. We excluded studies that compared subjects of different ages in the ICU but with missing mechanical ventilation data. Two of us (RSC and FV) screened all the studies from the databases for eligibility based on the titles and abstracts. Each of us selected some of the citations that were suspected to meet the eligibility criteria for the review. On identifying a citation as potentially relevant, one of us (RSC or FV) obtained the full article for review in detail to decide on that article's inclusion or exclusion.
Disagreements were resolved by consultation with a third author (AF), who then made the decision on a study's inclusion or elimination. We removed duplicates. One of us (RSC) contacted investigators of the studies reviewed for clarification and retrieval of reported and unreported relevant data. In some studies that included 3 comparative groups, the cutoff point for the age for inclusion in the study in the different subgroups was performed by one of us (RSC) on the basis of the characteristics of the study.

The data extraction was performed through the use of a prespecified data-extraction form. For each study, we detailed the following when present: characteristics of the study design, the inclusion criteria in relation to age, the selection of the groups for comparison, the number of subjects in each age group, and the presence of confounding factors. We also evaluated the following variables: severity scores, length of stay in both the ICU and the hospital, and the presence of ventilator-associated pneumonia. The primary outcome was to determine mortality in subjects ages $\geq 65 \mathrm{y}$ who received mechanical ventilation in the ICU compared with subjects ages $<65 \mathrm{y}$. We aimed to report hospital mortality; but, if that information was not present, then we considered mortality in the ICU. The secondary outcomes were to determine severity scores, lengths of stay in the ICU, lengths of stay in the hospital, and the presence of ventilator-associated pneumonia. Also, according to the statement in the Cochrane Handbook ${ }^{7}$ for the primary outcome of mortality, we performed the following subgroup analysis: subjects with ages $65 \mathrm{y}$ as a cutoff point with ARDS $^{8}$ and subjects ages 70 and $80 \mathrm{y}$ as the cutoff point.

Assessments of the methodological quality of the studies included in the primary outcome were performed by 2 of us (RSC and FV). We used 26 of the 27 items on the checklist of Downs and Black. ${ }^{9}$ Item 27, which is related to power, was extracted from a modified version of this checklist. ${ }^{10}$ This checklist comprises the assessment of the differences among subjects in different intervention groups (ie, the selection bias); the distribution of principal confounders; and the presence of performance, detection, and attrition biases. ${ }^{10}$ The scale of the overall score ranges from 0 to 29. The scores were also expressed as percentages. ${ }^{11}$ Scores between 80 and $100 \%$ are considered very good, 70 and $79 \%$ are good, and those between 50\% and $69 \%$ are considered fair. ${ }^{11}$ We assessed the quality of the body of evidence associated with the outcomes according to the GRADE (Grading of Recommendations Assessment, Development, and Evaluation) criteria guidelines. ${ }^{12} \mathrm{We}$ also investigated whether an adjustment was made for confounders in each of the studies included. ${ }^{13}$

We combined the studies through a meta-analysis. Odds ratio (OR) measurements at a $95 \%$ CI were used as estimates of the relationship between the older and younger subjects, this parameter being the appropriate statistic when 


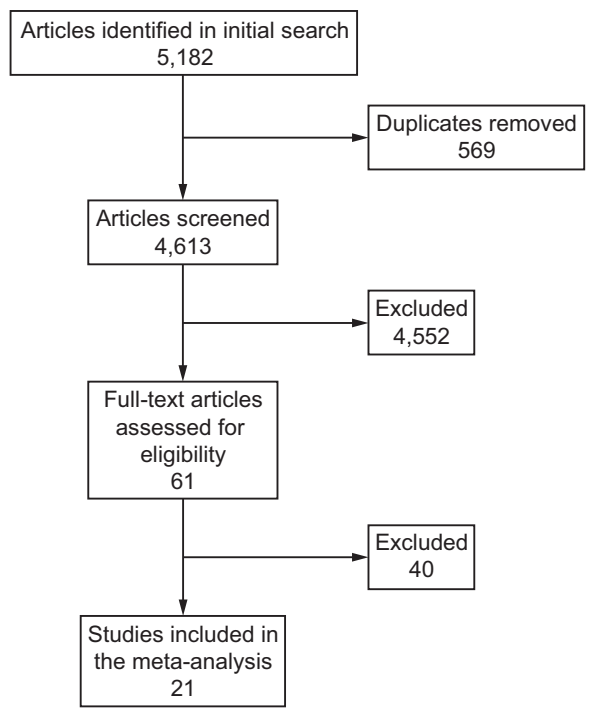

Fig. 1. Flow chart.

the logistic regression is used to adjust for confounding factors. The variation in the results of the studies was evaluated by drawing a forest plot, whereas the statistical heterogeneity was assessed by the $\mathrm{I}^{2}$ test at a $95 \% \mathrm{CI},{ }^{14}$ thereby estimating the percentage of total variance among studies that was attributable to heterogeneity rather than to chance. ${ }^{15}$ When no significant statistical heterogeneity was found $\left(\mathrm{I}^{2}<20 \%\right)$, the fixed-effect model was used; whereas, when $\mathrm{I}^{2}$ was $\geq 20 \%$, (which indicates moderate-to-high levels of heterogeneity), a random-effects model was used. In secondary outcomes, for continuous data, we use mean difference. All statistical analyses were performed with Review Manager version 5.3 (The Nordic Cochrane Center, The Cochrane Collaboration, Copenhagen, Denmark).

\section{Results}

\section{Identification of the Studies}

The flow diagram depicted in Figure 1 delineates the process used for the identification of the eligible studies. Of the 5,182 citations, after discarding the duplicates and revising the abstracts, we identified 61 potentially relevant studies. No ongoing studies were found. One study was in Chinese and required translation. ${ }^{16}$ During the evaluation of the full text of the articles, 40 studies were discarded. Finally, on the basis of a quantitative synthesis, 21 studies were included (11 studies included in the primary outcome plus 10 studies included in the subgroup analysis).

\section{Primary Outcome}

All the studies included were cohort studies, 6 were retrospective, ${ }^{16-21}$ and 5 were prospective. ${ }^{22-26}$ Three stud- ies compared several groups according to age and, subsequently, to perform the meta-analysis, these groups were divided into 2 groups, with an age cutoff point of $65 \mathrm{y} \cdot 19,21,23$ Four studies contained only subjects with ARDS. 16,22,25,26 The control group was variable in age among the studies. In 2 studies, the ages were between 45 and $64 \mathrm{y} .{ }^{16,18}$ In another study, the ages were between 55 and $64 \mathrm{y} ;{ }^{23}$ and, in the rest of the studies, all the subjects were $<64$ y old. The characteristics of the studies included are summarized in Table 1.

As evaluated according to the checklist of Downs and Black, ${ }^{9} 10$ studies averaged between 50 and 69\% (a fair study quality) ${ }^{16-23,25,26}$; one averaged between 70 and $79 \%$ (a good study quality). ${ }^{24}$ All 11 studies reported on mortality, ${ }^{16-26} 7$ reported on hospital mortality, 17,20,21,23-26 and 5 reported on ICU mortality. ${ }^{16,18,19,22,24}$ We pooled all those studies and used a random-effects model because the $\mathrm{I}^{2}$ value was $71 \%$. The subjects ages $\geq 65 \mathrm{y}$ were found to have a higher mortality than those younger than that cutoff age (OR 1.80, 95\% CI 1.56-2.08; $P<.001$ (Fig. 2).

\section{Sensitivity Analysis}

To assess the robustness of the primary outcome, we performed sensitivity analyses and separated the studies that registered hospital mortality from those studies that recorded mortality in the ICU. We evaluated hospital mortality in 7 studies and by using a random-effects model because the $\mathrm{I}^{2}$ was $72 \%$, found a statistically significant difference between the 2 groups (OR 1.90, 95\% CI 1.60-2.26; $P<.001$ (see supplementary materials at http://www.rcjournal.com). ${ }^{17,20,21,23-26}$ We then evaluated ICU mortality in 5 studies ${ }^{16,18,19,22,24}$; and with the random-effects model likewise being used because the $\mathrm{I}^{2}$ was $40 \%$, we also obtained a statistically significant difference between the 2 groups (OR 1.47, 95\% CI $1.18-1.83, P<.001$ (see supplementary materials at http://www.rcjournal.com). The quality of the evidence and strength of the recommendation (ie, GRADE) for these 3 outcomes were ranked as very low (Table 2).

\section{Secondary Outcomes}

Severity Scores. The scores used were the following: APACHE II, ${ }^{27}$ APACHE III, ${ }^{28}$ Simplified Acute Physiology Score II, ${ }^{29}$ and Acute physiology score (the score considered the acute physiologic variables included in the Simplified Acute Physiology Score II or APACHE III). We pooled 3 studies that used APACHE II (which trials included means \pm SDs), used the fixed-effect model because the $\mathrm{I}^{2}$ statistic was $0 \%$, and found statistically significant differences between the 2 groups (mean difference 3.07, 95\% CI 2.52-3.61, $P<.001$ (Fig. 3). ${ }^{16,18,24}$ 


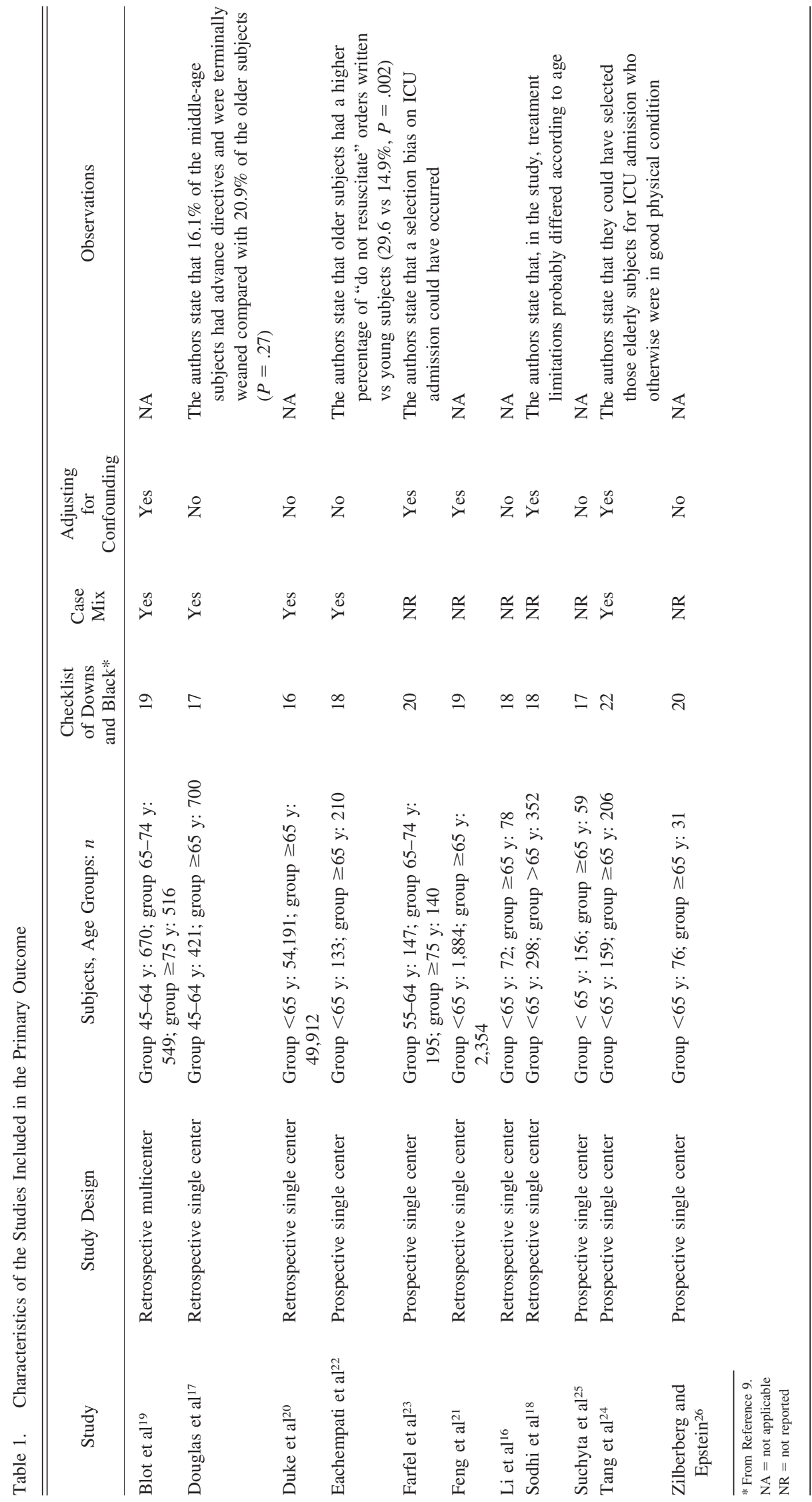




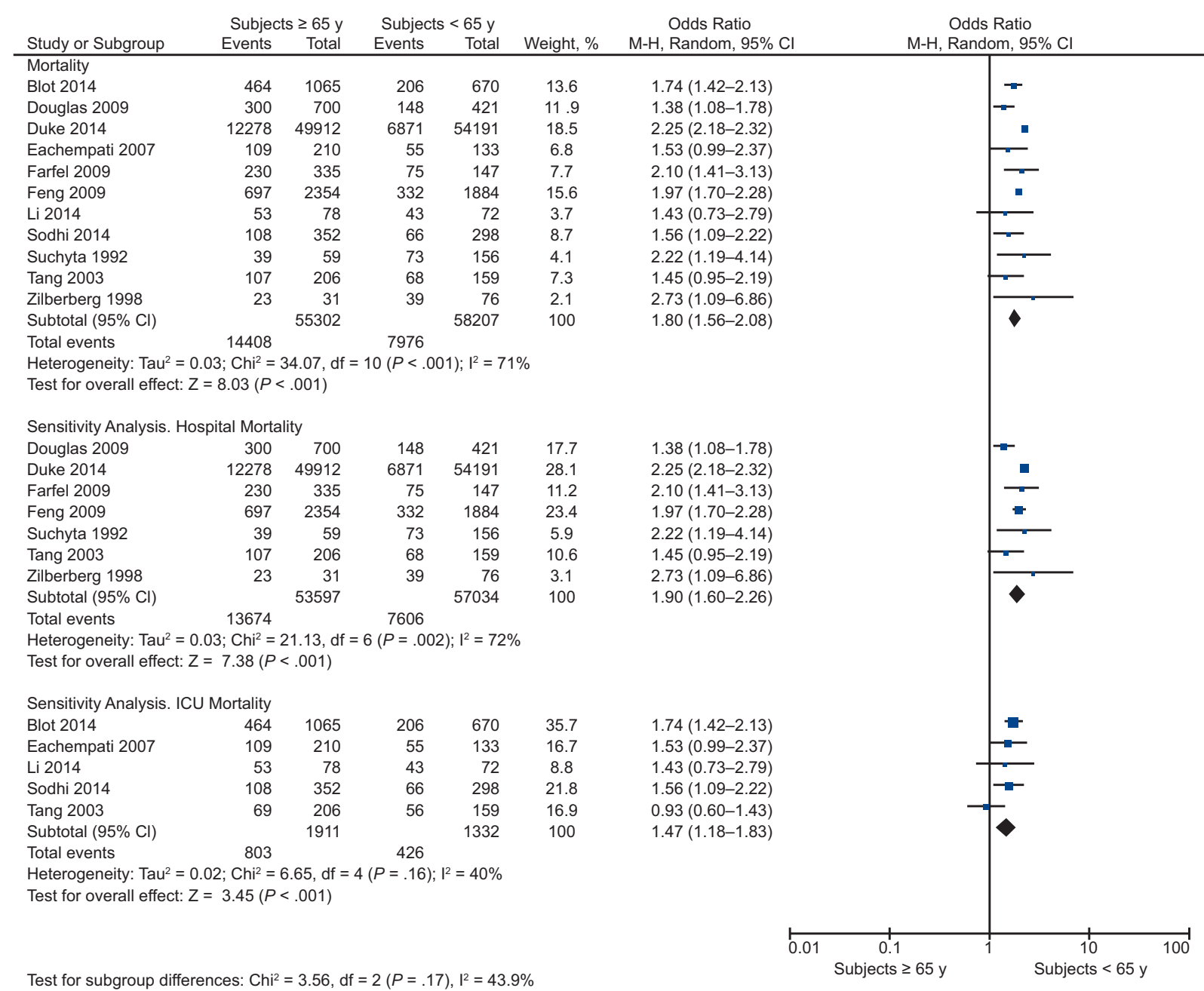

Fig. 2. Primary outcome. Forest plot of comparisons between subjects $\geq 65$ y and subjects $<65 \mathrm{y}$. Mortality, sensitivity analysis: hospital mortality, and sensitivity analysis: ICU mortality.

Length of Stay in the ICU. In this meta-analysis, we pooled 3 studies and used the random-effects model because the $\mathrm{I}^{2}$ statistic was $82 \%$, and found no statistically significant differences between the 2 groups (mean difference $1.27 \mathrm{~d}$, $95 \% \mathrm{CI},-0.82$ to $3.36 \mathrm{~d} ; P=.23$ (Fig. 3). ${ }^{17,18,24}$

Length of Stay in the Hospital. In this meta-analysis, we pooled 2 studies, used the fixed-effect model because the $\mathrm{I}^{2}$ statistic was $0 \%$ and, likewise, obtained no statistically significant differences between the 2 groups (mean difference $1.29 \mathrm{~d}, 95 \% \mathrm{CI},-0.71$ to $3.29 \mathrm{~d}$; $P=.21$ ) (Fig. 3). ${ }^{17,24}$

The quality of the evidence and the strength of the recommendation (ie, GRADE) for these 3 outcomes (severify scores, length of stay in the ICU, and length of stay in the hospital) were ranked as low or very low (Table 2).

Ventilator-Associated Pneumonia. We could not pool data for the meta-analysis of this variable and thus as- sessed the presence of ventilator-associated pneumonia as a number and the percentage of the total in the age group. Blot et al ${ }^{19}$ compared 3 groups and found no differences: subjects ages $\geq 75 \mathrm{y}, 73(14.1 \%)$; subjects ages $65-74 \mathrm{y}$, 104 (18.9\%); and subjects ages 45-64 y, 103 (15.4\%); $P=.08$. Eachempati et $\mathrm{al}^{22}$ likewise found no significant difference between the groups: subjects ages $\geq 65 \mathrm{y}, 144$ $(68.4 \%)$; and subjects ages $<65 \mathrm{y}, 86(64.7 \%) ; P=.69$.

\section{Subgroup Analysis}

Subjects Ages $\geq 65 \mathrm{y}$ and With ARDS Compared With Subjects Ages $<\mathbf{6 5} \mathbf{y}$ and With ARDS. Four studies were pooled. ${ }^{16,22,25,26}$ Two studies reported hospital mortality, ${ }^{25,26}$ and 2 studies reported ICU mortality. ${ }^{16,22}$ In this meta-analysis, the use of a fixed-effect model, because $\mathrm{I}^{2}$ was $0 \%$, revealed a statistically significant difference between the 2 groups (OR 1.76, 95\% CI 1.30-2.36; $P<.001$ (Fig. 4). 


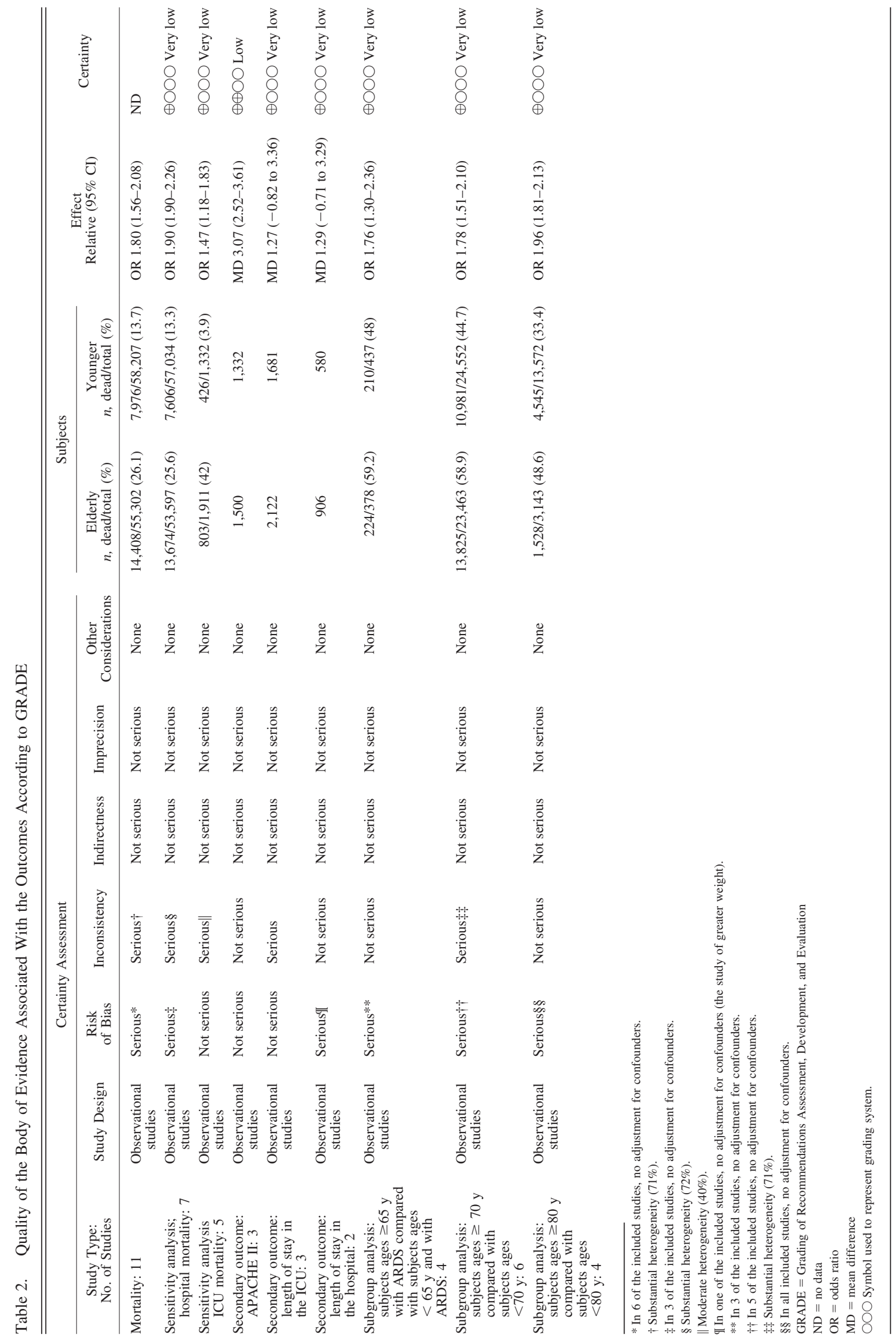




\section{Mortality in Older Mechanically Ventilated Individuals}

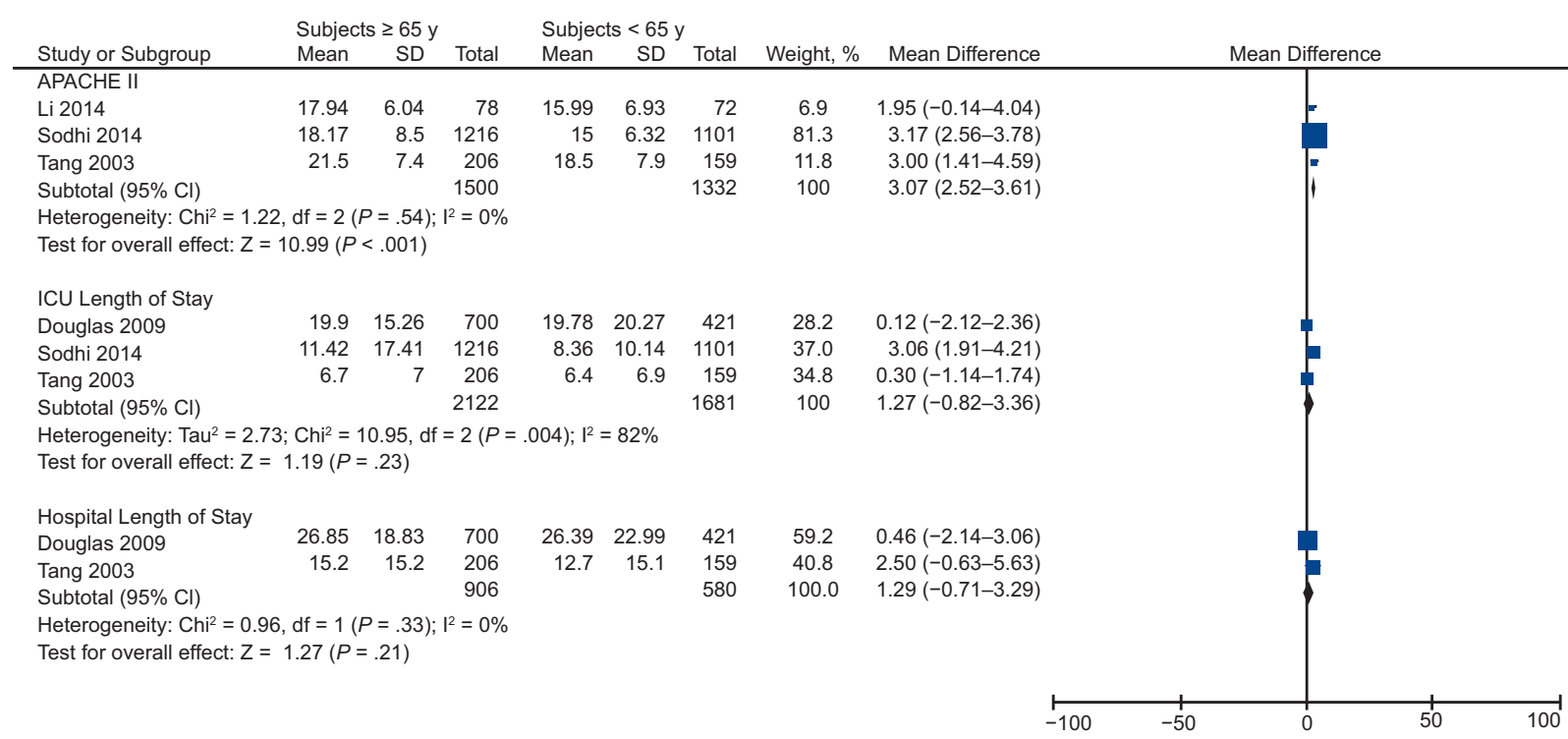

Test for subgroup differences: $\mathrm{Chi}^{2}=8.65, \mathrm{df}=2(P=.01), \mathrm{I}^{2}=76.9 \%$

Fig. 3. Secondary outcomes. APACHE II, ICU length of stay, and hospital length of stay.

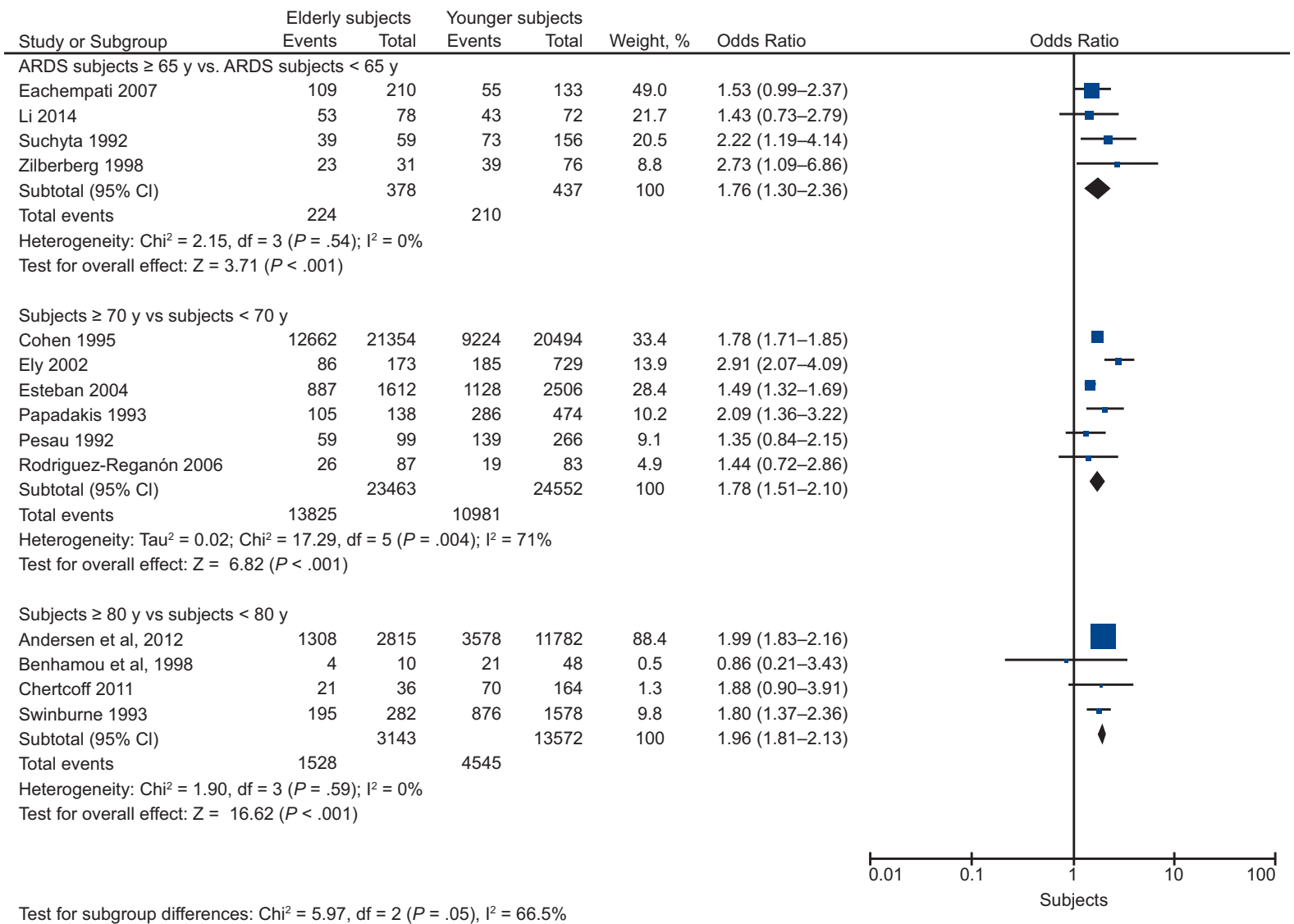

Fig. 4. Subgroup analysis. Forest plot of comparisons between older and younger subjects. Subjects with ARDS, and subjects with 70 and $80 \mathrm{y}$ of age as cutoff points. 
Subjects Ages $\geq 70$ y Compared With Subjects Ages $<70$ y. Six studies were included. ${ }^{30-35}$ For this metaanalysis, 4 studies $^{31,32,34,35}$ reported hospital mortality, one study ${ }^{33}$ reported ICU mortality, and one study ${ }^{30}$ reported mortality at $28 \mathrm{~d}$. By using the random-effects model, because $\mathrm{I}^{2}$ was $71 \%$, we found a statistically significant difference between the 2 groups (OR 1.78, 95\% CI 1.512.10; $P<.001$ ) (Fig. 4).

Subjects Ages $\geq 80$ y Compared With Subjects Ages $<\mathbf{8 0}$ y. In this analysis, according to the outcomes presented in the studies included, we considered hospital mortality. Four studies were pooled, and the fixed-effect model was used because the $\mathrm{I}^{2}$ statistic was $0 \%$, and statistically significant differences were found between the 2 groups (OR 1.96, 95\% CI 1.81-2.13; $P<.001$ ) (Fig. 4). ${ }^{36-39}$

The quality of the evidence and strength of the recommendation (ie, GRADE) for these 3 outcomes (subjects ages $\geq 65 \mathrm{y}$ and with ARDS compared with subjects ages $<65 \mathrm{y}$ and with ARDS; subjects ages $\geq 70 \mathrm{y}$ compared with subjects ages $<70 \mathrm{y}$; and subjects ages $\geq 80$ y compared with subjects ages $<80$ y) were ranked as very low (Table 2). The characteristics of the studies included in the subgroup analysis are summarized in Table 3.

\section{Discussion}

This review found that the mortality rate of subjects ages $\geq 65 \mathrm{y}$ who received mechanical ventilation in ICUs was significantly higher than in younger subjects. With regard to secondary outcomes, the stay in the ICU and in the hospital, as well as the presence of ventilator-associated pneumonia, were not different between the groups, albeit elderly subjects had a higher APACHE II score. A subgroup analysis that compared elderly with younger subjects and that evaluated different age limits, including one comparison between patients with ARDS, also revealed a higher mortality in the older subjects. Despite these results, the evidence as assessed by the GRADE, was considered very low. In addition, for the primary outcome, only one study reached a good quality score (according to the checklist of Downs and Black ${ }^{9},{ }^{24}$ and several of the studies involved case mix. ${ }^{17,19,20,22,24}$ For this reason, we also need to emphasize that the inadequate methodological quality of the available evidence with respect to mortality in elderly subjects who received mechanical ventilation prevented us from drawing definitive conclusions.

We evaluated only subjects who received mechanical ventilation because we considered that mechanical ventilation was a determining element in the prognosis of elderly patients. Certain studies found mechanical ventilation to be a risk factor associated with mortality in subjects ages $\geq 65 \mathrm{y},{ }^{40}$ in subjects ages $\geq 80 \mathrm{y},{ }^{41}$ in elderly sub- jects with trauma, ${ }^{42}$ or in older subjects with acute ischemic stroke and who are critically ill. ${ }^{43}$ In addition, 2 of the studies included in this review that separated elderly subjects according to the mechanical-ventilation requirement concluded that higher mortality occurred in the subjects who received mechanical ventilation. ${ }^{18,23}$ Therefore, the mechanical-ventilation requirement placed an additional weight of risk in the prognosis of mortality in elderly patients, a conclusion in concordance with the outcomes of our review, in which we found increased mortality in elderly subjects who received mechanical ventilation.

For the primary outcome, we accordingly found a higher mortality of subjects in the ICU and ages $\geq 65 \mathrm{y}$, in accordance with what has been shown in other studies of subjects who either received prolonged mechanical ventilation ${ }^{44}$ or had blunt trauma. ${ }^{45}$ We must emphasize here that, when we performed a sensitivity analysis by separating the studies that registered hospital mortality from those that recorded mortality in the ICU, we consistently found the same result. In addition, in subjects with ARDS, the result of the 4 studies included in the subgroup analysis also indicated a higher mortality in the elderly subject group. ${ }^{16,22,25,26}$ Our findings, therefore, were consistent with previous reports on cohorts of subjects with ARDS as well as with a systematic review that found an association between age and mortality. $46-48$

Certain investigators indicated that the stay in the ICU and in the hospital are similar in young and elderly patients, ${ }^{49,50}$ an observation that was consistent with the results garnered in this review but differed from the difference obtained specifically in ICU mortality. A possible explanation for this discrepancy could be that mechanical ventilation stabilizes and homogenizes patients in the acute phase of a disease but does not modify the impact of the severity of the disease, the underlying comorbidities, or the physiologic limitations in response to injury, as has likewise been proposed by other investigators. ${ }^{17,38}$

We used the APACHE II as a marker of disease severity and found that the score was increased in elderly patients. For that reason, consistent with previous findings, ${ }^{51,52}$ we considered that the general prognosis in elderly patients mainly depends on the severity of the illness. It should be noted that Vosylius et al, ${ }^{53}$ in a study that assessed the determinants of outcome in elderly subjects admitted to the ICU, in which the Simplified Acute Physiology Score II was included, considered that a greater level of severity of illness is directly related to increasing points assigned to elderly subjects in the Simplified Acute Physiology Score II and other scoring systems. In addition, Knaus et al ${ }^{54}$ found that only $3.4 \%$ of the predictive power of mortality in the APACHE III system was attributed to age. All these elements support the idea that APACHE II would mainly be associated with the severity of the disease. 


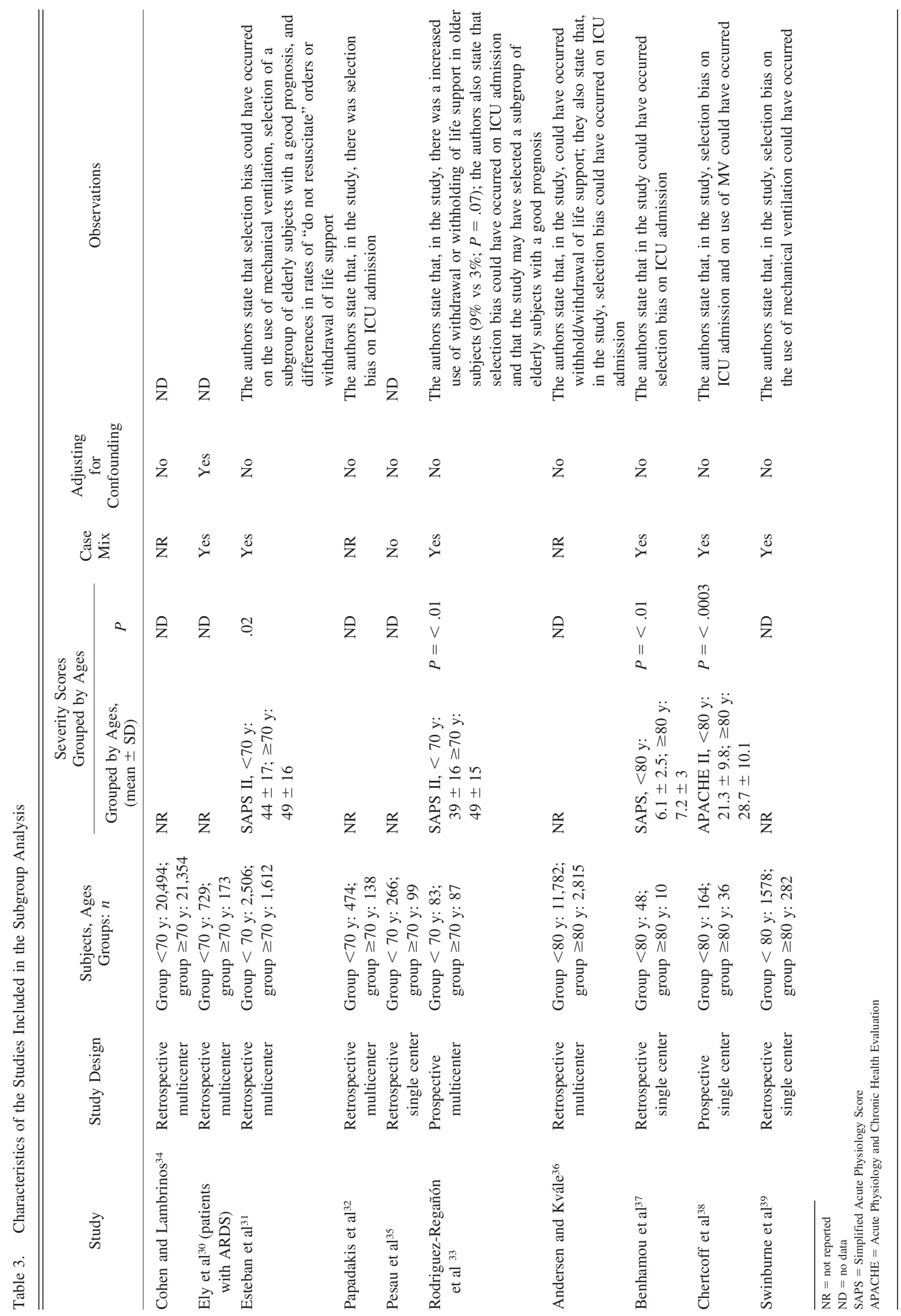


The main strength of this review was that the exhaustive screening of the relevant literature involved a high-sensitivity systematic search of the main available databases without language restriction through the use of standardized techniques. For this reason, we believed that the studies included in this review constituted all the evidence on the assessment of elderly subjects in the ICU who received mechanical ventilation that was readily available up to the moment of carrying out the literature search.

There were limitations of this review. First, in the primary outcome, 8 studies ${ }^{17,19,20-22,24-26}$ included subjects in the control group ages 18 to $64 \mathrm{y}$; therefore, the selection may have generated an additional bias because a comparison between more homogeneous populations (ie, subjects ages $\geq 45$ y) would have been preferable. Second, we used hospital or ICU mortality because short-term survival may clearly benefit from ICU treatment (in this instance, through the use of mechanical ventilation). Certain authors, however, considered that the assessment of mortality at 6 months or a year was probably a more appropriate end point. ${ }^{55,56}$ Third, 3 studies involved an increased use of withdrawal or withholding of life support, ${ }^{17,22,33}$ although, in 2 of these studies, ${ }^{17,33}$ the degree of withdrawal was balanced between the groups. In contrast, Eachempati et $\mathrm{al}^{22}$ reported a higher percentage of cases that involved do not resuscitate orders in older subjects; this could modify the outcomes. For this reason, the conclusions drawn should, nevertheless, be regarded with some degree of caution. Fourth, due to the cutoffs in relation to age (which was specified in the protocol), some important studies with different cutoff points may have been excluded from the review. However, according to the results obtained, we believed that there would be no significant changes.

\section{Conclusions}

This review found that the mortality rates in elderly subjects who received mechanical ventilation, with special emphasis on those ages $\geq 65 \mathrm{y}$, were higher than in younger subjects, although the quality of the evidence remained low. Our analysis supports the notion that the requirement for mechanical ventilation and the severity of illness, and not the patient's age, are decisive elements in the prognosis of elderly patients. The intensification of research on the treatment of this growing population of older patients in the ICU, and especially those who require mechanical ventilation, along with an improvement in the evidence quality will lead to better informed decisions in managing elderly patients in the ICU.

\section{ACKNOWLEDGMENTS}

The authors thank Carlos Apezteguía, who reviewed and supervised the manuscript critically, Marcela Paladino, who contributed with the design of the review, and Donald F Haggerty, who edited the final version of the manuscript.

\section{REFERENCES}

1. Angus DC, Kelley MA, Schmitz RJ, White A, Popovich J Jr; Committee on Manpower for Pulmonary and Critical Care Societies (COMPACCS). Caring for the critically ill patient. Current and projected workforce requirements for care of the critically ill and patients with pulmonary disease: can we meet the requirements of an aging population? JAMA 2000;284(21):2762-2770.

2. Bagshaw SM, Webb SA, Delaney A, George C, Pilcher D, Hart GK, Bellomo R. Very old patients admitted to intensive care in Australia and New Zealand: a multi-centre cohort analysis. Crit Care 2009; 13(2):R45.

3. Brandberg C, Blomqvist $\mathrm{H}$, Jirwe $\mathrm{M}$. What is the importance of age on treatment of the elderly in the intensive care unit? Acta Anaesthesiol Scand 2013;57(6):698-703.

4. Ely EW, Evans GW, Haponik EF. Mechanical ventilation in a cohort of elderly patients admitted to an intensive care unit. Ann Intern Med 1999;131(2):96-104.

5. Santana Cabrera L, Sánchez-Palacios M, Hernández Medina E, Lorenzo Torrent R, Martínez Cuéllar S, Villanueva Ortiz A. [Outcome of the critical patient according to the sex and the age]. Med Intensiva 2009;33(4):161-165.

6. Stroup DF, Berlin JA, Morton SC, Olkin I, Williamson GD, Rennie $\mathrm{D}$, et al. Meta-analysis of observational studies in epidemiology - a proposal for reporting. JAMA 2000;283(15):2008-2012.

7. Higgins JPT, Green S, editors. Cochrane Handbook for Systematic Reviews of Interventions, Version 5.1.0 [updated Mar 2011]. The Cochrane Collaboration, 2011. Available at http://handbook.cochrane. org. Accessed March 7, 2016

8. ARDS Definition Task Force, Ranieri VM, Rubenfeld GD, Thompson BT, Ferguson ND, Caldwell E, et al. Acute respiratory distress syndrome: the Berlin Definition. JAMA 2012;307(23):2526-2533.

9. Downs SH, Black N. The feasibility of creating a checklist for the assessment of the methodological quality both of randomised and non-randomised studies of health care interventions. J Epidemiol Community Health 1998;52(6):377-384.

10. Kennelly J. Methodological approach to assessing the evidence. In: Handler A. Reducing racial/ethnic disparities in reproductive and perinatal outcomes: The evidence from population-based interventions, New York: Springer-Verlag; 2011:7-19.

11. Machado M, Bajcar J, Guzzo GC, Einarson TR. Sensitivity of patient outcomes to pharmacist interventions. Part II: Systematic review and meta-analysis in hypertension management. Ann Pharmacother 2007; 41(11):1770-1781.

12. Guyatt GH, Oxman AD, Kunz R, Vist GE, Falck-Ytter Y, Schünemann HJ, GRADE Working Group. What is "quality of evidence" and why is it important to clinicians? BMJ 2008;336(7651):995-998.

13. Deeks JJ, Dinnes J, D'Amico R, Sowden AJ, Sakarovitch C, Song F, et al.; International Stroke Trial Collaborative Group; European Carotid Surgery Trial Collaborative Group. Evaluating non-randomised intervention studies. Health Technol Assess 2003;7(27):iii-x, 1-173.

14. Higgins JP, Thompson SG. Quantifying heterogeneity in a metaanalysis. Stat Med 2002;21(11):1539-1558.

15. Higgins JP, Thompson SG, Deeks JJ, Altman DG. Measuring inconsistency in meta-analyses. BMJ 2003;327(7414):557-560.

16. Li Q, Zhang J, Wan X. [Analysis of characteristics and related risk factors of prognosis in elderly and young adult patients with acute respiratory distress syndrome]. Zhonghua Wei Zhong Bing Ji Jiu Yi Xue 2014;26(11):794-798.

17. Douglas SL, Daly BJ, O’Toole EE, Kelley CG, Montenegro H. Age differences in survival outcomes and resource use for chronically critically ill patients. J Crit Care 2009;24(2):302-310.

18. Sodhi K, Singla MK, Shrivastava A, Bansal N. Do Intensive Care Unit treatment modalities predict mortality in geriatric patients: An 


\section{Mortality in Older Mechanically Ventilated Individuals}

observational study from an Indian Intensive Care Unit. Indian J Crit Care Med 2014;18(12):789-795.

19. Blot S, Koulenti D, Dimopoulos G, Martin C, Komnos A, Krueger WA, et al.; EU-VAP Study Investigators. Prevalence, risk factors, and mortality for ventilator-associated pneumonia in middle-aged, old, and very old critically ill patients. Crit Care Med 2014;42(3): 601-609.

20. Duke GJ, Barker A, Knott CI, Santamaria JD. Outcomes of older people receiving intensive care in Victoria. Med J Aust 2014;200(6): 323-326.

21. Feng Y, Amoateng-Adjepong Y, Kaufman D, Gheorghe C, Manthous CA. Age, duration of mechanical ventilation, and outcomes of patients who are critically ill. Chest 2009;136(3):759-764.

22. Eachempati SR, Hydo LJ, Shou J, Barie PS. Outcomes of acute respiratory distress syndrome (ARDS) in elderly patients. J Trauma 2007;63(2):344-350.

23. Farfel JM, Franca SA, Sitta Mdo C, Filho WJ, Carvalho CR. Age, invasive ventilatory support and outcomes in elderly patients admitted to intensive care units. Age and ageing 2009;38(5):515-520.

24. Tang EY, Hsu LF, Lam KN, Pang WS. Critically ill elderly who require mechanical ventilation: the effects of age on survival outcomes and resource utilisation in the medical intensive care unit of a general hospital. Ann Acad Med Singapore 2003;32(5):691-696.

25. Suchyta MR, Clemmer TP, Elliott CG, Orme JF Jr, Weaver LK. The adult respiratory distress syndrome. A report of survival and modifying factors. Chest 1992;101(4):1074-1079.

26. Zilberberg MD, Epstein SK. Acute lung injury in the medical ICU: comorbid conditions, age, etiology, and hospital outcome. Am J Respir Crit Care Med 1998;157(4 Pt 1):1159-1164.

27. Knaus WA, Draper EA, Wagner DP, Zimmerman JE. APACHE II: a severity of disease classification system. Crit Care Med 1985; 13(10):818-829.

28. Knaus WA, Wagner DP, Draper EA, Zimmerman JE, Bergner M, Bastos PG, et al. The APACHE III prognostic system. Risk prediction of hospital mortality for critically ill hospitalized adults. Chest 1991;100(6):1619-1636.

29. Le Gall JR, Lemeshow S, Saulnier F. A new Simplified Acute Physiology Score (SAPS II) based on a European/North American multicenter study. JAMA 1993;270(24):2957-2963.

30. Ely EW, Wheeler AP, Thompson BT, Ancukiewicz M, Steinberg $\mathrm{KP}$, Bernard GR. Recovery rate and prognosis in older persons who develop acute lung injury and the acute respiratory distress syndrome. Ann Intern Med 2002;136(1):25-36.

31. Esteban A, Anzueto A, Frutos-Vivar F, Alía I, Ely EW, Brochard L, et al.; Mechanical ventilation international study group. Outcome of older patients receiving mechanical ventilation. Intensive Care Med 2004;30(4):639-646.

32. Papadakis MA, Lee KK, Browner WS, Kent DL, Matchar DB, Kagawa MK, et al. Prognosis of mechanically ventilated patients. West J Med 1993;159(6):659-664.

33. Rodríguez-Regañón I, Colomer I, Frutos-Vivar F, Manzarbeitia J, Rodríguez-Mañas L, Esteban A. Outcome of older critically ill patients: a matched cohort study. Gerontology 2006;52(3):169-173.

34. Cohen IL, Lambrinos J. Investigating the impact of age on outcome of mechanical ventilation using a population of 41,848 patients from a statewide database. Chest 1995;107(6):1673-1680.

35. Pesau B, Falger S, Berger E, Weimann J, Schuster E, Leithner C, Frass M. Influence of age on outcome of mechanically ventilated patients in an intensive care unit. Crit Care Med 1992;20(4):489-492.

36. Andersen FH, Kvåle R. Do elderly intensive care unit patients receive less intensive care treatment and have higher mortality? Acta anaesthesiol Scand 2012;56(10):1298-1305.

37. Benhamou D, Muir JF, Melen B. Mechanical ventilation in elderly patients. Monaldi Arch Chest Dis 1998;53(5):547-551.
38. Chertcoff FJ, Quadrelli S, Soloaga ED, Chertcoff ML, Poliszuk J, Pérez Prieto F. [Mechanical ventilation. Influence of the age in the outcome]. Medicina 2011;71(1):27-32.

39. Swinburne AJ, Fedullo AJ, Bixby K, Lee DK, Wahl GW. Respiratory failure in the elderly. Analysis of outcome after treatment with mechanical ventilation. Arch Intern Med 1993;153(14):1657-1662.

40. Stein Fde C, Barros RK, Feitosa FS, Toledo DO, Silva Junior JM, Isola AM, et al. Prognostic factors in elderly patients admitted in the intensive care unit. Rev Bras Ter Intensiva 2009;21(3):255-261.

41. Lown DJ, Knott J, Rechnitzer T, Maclsaac C. Predicting short-term and long-term mortality in elderly emergency patients admitted for intensive care. Crit Care Resusc 2013;15(1):49-55.

42. Chan LY, Moran JL, Clarke C, Martin J, Solomon PJ. Mortality and cost outcomes of elderly trauma patients admitted to intensive care and the general wards of an Australian tertiary referral hospital. Anaesth Intensive Care 2009;37(5):773-783.

43. Golestanian E, Liou JI, Smith MA. Long-term survival in older critically ill patients with acute ischemic stroke. Crit Care Med 2009; 37(12):3107-3113

44. Combes A, Costa MA, Trouillet JL, Baudot J, Mokhtari M, Gibert C, Chastre J. Morbidity, mortality, and quality-of-life outcomes of patients requiring $>$ or $=14$ days of mechanical ventilation. Crit Care Med 2003;31(5):1373-1381.

45. Taylor MD, Tracy JK, Meyer W, Pasquale M, Napolitano LM. Trauma in the elderly: intensive care unit resource use and outcome. J Trauma 2002;53(3):407-414

46. Brun-Buisson C, Minelli C, Bertolini G, Brazzi L, Pimentel J, Lewandowski K, et al.; ALIVE Study Group. Epidemiology and outcome of acute lung injury in European intensive care units. Results from the ALIVE study. Intensive Care Med 2004;30(1):51-61

47. Rubenfeld GD, Caldwell E, Peabody E, Weaver J, Martin DP, Neff $\mathrm{M}$, et al. Incidence and outcomes of acute lung injury. N Engl J Med 2005;353(16):1685-1693.

48. Phua J, Badia JR, Adhikari NK, Friedrich JO, Fowler RA, Singh JM, et al. Has mortality from acute respiratory distress syndrome decreased over time?: A systematic review. Am J Respir Crit Care Med 2009;179(3):220-227.

49. Boumendil A, Somme D, Garrouste-Orgeas M, Guidet B. Should elderly patients be admitted to the intensive care unit? Intensive Care Med 2007;33(7):1252.

50. Al-Dorzi HM, Tamim HM, Mundekkadan S, Sohail MR, Arabi YM Characteristics, management and outcomes of critically ill patients who are 80 years and older: a retrospective comparative cohort study. BMC Anesthesiol 2014;14:126.

51. Somme D, Maillet JM, Gisselbrecht M, Novara A, Ract C, Fagon JY. Critically ill old and the oldest-old patients in intensive care: short- and long-term outcomes. Intensive Care Med 2003;29(12): 2137-2143.

52. Chelluri L, Pinsky MR, Donahoe MP, Grenvik A. Long-term outcome of critically ill elderly patients requiring intensive care. JAMA 1993;269(24):3119-3123.

53. Vosylius S, Sipylaite J, Ivaskevicius J. Determinants of outcome in elderly patients admitted to the intensive care unit. Age Ageing 2005;34(2):157-162.

54. Knaus WA, Wagner DP, Zimmerman JE, Draper EA. Variations in mortality and length of stay in intensive care units. Ann Intern Med 1993;118(10):753-761.

55. Dardaine V, Dequin PF, Ripault H, Constans T, Giniès G. Outcome of older patients requiring ventilatory support in intensive care: impact of nutritional status. J Am Geriatr Soc 2001;49(5):564-570.

56. Lieberman D, Nachshon L, Miloslavsky O, Dvorkin V, Shimoni A. How do older ventilated patients fare? A survival/functional analysis of 641 ventilations. J Crit Care 2009;24(3):340-346. 